\title{
Nivel de conocimiento sobre prevención de caries dental en universitarios
}

\section{Dental caries prevention related knowledge among students}

Clarisse Virginia Díaz-Reissner ${ }^{1} \otimes$ Researchgate, Nohelia María Pérez-Bejarano ${ }^{2 \otimes}$, Diana Alicia Sanabria-Vázquez ${ }^{3 凶}$, Marta Inés Ferreira-Gaona ${ }^{4}$ Academia , Natalia Cristina Cueto-González ${ }^{5 \otimes}$ , David Alessandro Urquhart-Barreto ${ }^{5 \boldsymbol{\Delta}}$, Maia Macarena Arce-Mena ${ }^{5 \boldsymbol{\Delta}}$, Luis Enrique LedesmaAmarilla ${ }^{5 凶}$

1. Odontóloga, Magíster en Estadística. Facultad de Odontología. Universidad del Pacifico. Asunción, Paraguay

2. Especialista en Odontopediatría. Facultad de Odontología. Universidad del Pacifico. Asunción, Paraguay.

3. Odontóloga. Especailista en Estética Dental. Facultad de Odontología. Universidad del Pacifico. Asunción, Paraguay.

4. Odontóloga. Especialista en Metodología de la Investigación. Facultad de Odontología. Universidad del Pacifico. Asunción, Paraguay

5. Estudiante de pregrado. Facultad de Odontología. Universidad del Pacifico. Asunción, Paraguay.

Fecha correspondencia:

Recibido: septiembre de 2015 .

Aceptado: junio de 2016.

\section{Forma de citar:}

Díaz-Reissner CV, Pérez-Bejarano

NM, Sanabria-Vázquez DA,

Ferreira-Gaona MI, Cueto-González

NC, Barreto DA, Arce-Mena MM,

Ledesma-Amarilla LE. Nivel de

conocimiento sobre prevención

de caries dental en universitarios.

Rev. CES Odont 2016; 29(1): 14-21.

Open Acces

(C) Derecho de autor

Licencia creative commons

Ética de publicaciones

Revisión por pares

Gestión por Open Journal System

ISSN 0120-971X

e-ISSN 2215-9185

Comparte

\section{Resumen}

Introducción: El conocimiento adecuado de aspectos sobre prevención de caries dental, puede resultar fundamental para mantener un estado de salud bucal óptimo. Objetivo: Determinar el nivel de conocimiento sobre prevención de caries dental en estudiantes de carreras distintas a Odontología de la Universidad del Pacífico, matriculados en el año 2015. Materiales y métodos: Estudio descriptivo de corte transversal, donde participaron 131 estudiantes, que completaron una encuesta con 10 preguntas cerradas sobre mecanismos de prevención de la caries dental. Resultados: Pertenecían al sexo femenino 63.4\%; procedían de Asunción 58,8\%, el promedio de edad fue de 20 años. Solo el 8,4\% respondió que bacterias que dañan los dientes aparecen en el niño desde que se transmite, considerando sólo un 25,1\% a la caries dental transmisible. El 41,2\% contestó que es tan importante la técnica de cepillado como la marca del cepillo. Sólo el 19,1\% cree que se debe realizar limpieza bucal desde el nacimiento, mientras que el 56,5\% desde que erupciona el primer diente. Así también, solo un 35,1\% consideró que los dientes deciduos cariados deben ser tratados para conservar el espacio de los permanentes. El nivel de conocimientos fue insuficiente (1-2 aciertos) en 8,4\%; aceptable (3-4 aciertos) en 43,5\%; ( $5-6$ aciertos) en 41,2\%; (7-8 aciertos) en 6,9\% y ninguno obtuvo excelente. Conclusiones: Menos de la mitad presentó conocimiento muy bueno sobre prevención de la caries dental, lo que indicaría que en la población de estudio se necesita promocionar estrategias para conseguir una buena salud bucodental.

Palabras clave: Estudiantes, Higiene bucal, Educación, Salud bucal.

\section{Abstract}

Introduction: Adequate knowledge of dental caries prevention may be critical to maintain optimal oral health status. objective: to determine the dental caries prevention related knowledge among Universidad del Pacífico students, in different faculties than Dentistry, enrolled in the year 2015. 
Materials and methods: A descriptive cross-sectional study conducted among 131 undergraduate students, who completed a survey of 10 closed questions on caries prevention mechanisms. Results: $63.4 \%$ were female; $58.8 \%$ came from Asunción city, the average age was 20 . Only $8.4 \%$ said bacteria that damage the teeth appear in the child right from the moment bacteria reach child's mouth and only $25.2 \%$ considered dental caries as transmissible. $41.2 \%$ consider brushing techniques and brush brand as very important. Only $19.1 \%$ believed that dental cleaning should be performed at birth, while $56.5 \%$ since the first tooth erupts. Likewise, only $35.1 \%$ considered temporary teeth decayed must be treated to keep space for future permanent teeth. Knowledge level was insufficient (1-2 hits) at 8.4\%; acceptable (3-4 hits) in 43.5\%; good (5-6 hits) in 41.2\%; very good (7-8 hits) on $6.9 \%$ and none got excellent. Conclusions: Less than half the students have good knowledge about dental caries prevention, which would indicate that the study population needed strategies to reach good oral health habits.

Keywords: Students, Oral hygiene, Education, Oral health.

\section{Introducción}

La caries dental es una enfermedad microbiana y multifactorial, producto del ataque de ácidos generados por las bacterias de la placa dental. Se considera multifactorial debido a que, para su desarrollo deben conjugarse diversos factores como: huésped susceptible, sustrato rico en hidratos de carbono, microorganismos y tiempo; por tanto se encuentra estrechamente relacionada con la dieta y también la composición del flujo salival $(1,2)$. Además, pueden influir otros factores de riesgo como puede ser el acceso a los servicios de salud, factores físico-ambientales, de comportamiento (3). Sin embargo, puede ser prevenida controlando la formación de la placa dental, mediante el cepillado dental regular y la baja ingesta de carbohidratos en comidas y bebidas azucaradas; si la placa dental no se remueve las bacterias que causan la caries dental se multiplican y adhieren a la superficie dental formando una película pegajosa, entonces las bacterias transforman en ácido los azúcares, dando lugar a la caries dental. Entre otros, el xilitol resulta una alternativa al azúcar, pues es un edulcorante natural que se cree ayuda a prevenir la caries dental (ㄴ).

Esta enfermedad puede llegar a afectar las condiciones generales de salud del individuo, teniendo un fuerte impacto sobre la morbilidad bucal y un elevado costo de tratamiento, lo que justifica la necesidad de diseñar e implementar estrategias y estudios efectivos sobre prevención y promoción de salud bucal (므). La falta de prevención genera más restauraciones, tratamiento periodontal, extracciones y prótesis dentales; por lo que se requiere una transformación de prioridad del tratamiento a prevención (6). Es por esto, que la necesidad de promover la práctica de la atención odontológica preventiva resulta relevante, pues los recursos disponibles para la atención de la salud en la mayoría de los países en desarrollo son insuficientes para apoyar la atención curativa tradicional de enfermedades dentales ()).

En Paraguay, la severidad de caries ha sido un problema por varios años; en 1999 el índice nacional CPO-D fue de 3,6 y 5,6 para 12 y 15 años respectivamente; con una necesidad de tratamiento del 46\%; mientras que en el 2008 el CPO-D fue de 2,8 y 3,3 respectivamente; lo que puede reflejar una ligera disminución. Esta diferencia podría deberse a la implementación de programas preventivos por parte de la Dirección de Salud Bucodental del Ministerio de Salud Pública y Bienestar Social $(\underline{8}, \underline{9})$. 
Todo problema de salud, puede ser prevenido comenzando con la promoción de la misma, educando a una población en referencia a un aspecto en particular, en este caso de la salud oral. Para que un programa de educación tenga mayor éxito, resultaría conveniente conocer en principio que nivel de conocimiento acerca del tema tiene dicha población. Por lo expuesto, este estudio se determinó el nivel de conocimiento sobre caries dental en estudiantes de la Universidad del Pacifico de la sede de Asunción, matriculados en el 2015, que servirá de base en el diseño de estrategias que colaboren en mejorar la situación de salud oral o mantenerla en óptimas condiciones.

\section{Materiales y métodos}

El diseño del estudio fue descriptivo de corte transversal. El protocolo de investigación fue aprobado por el Comité de Ética de la Universidad del Pacifico (UP). La población de estudio quedó constituida por estudiantes de pregrado de la Universidad del Pacífico (UP), matriculados en el año 2015, de la sede de Asunción. La UP cuenta con 1341 estudiantes en la mañana, tarde y noche. El cálculo del tamaño de la muestra se realizó con una precisión del 8,5\% mediante la estimación de una proporción con un intervalo de confianza para poblaciones finitas al 95\% bilateral, asumiendo una proporción del $50 \%$ por el desconocimiento de la variable de interés. Para un tamaño muestral de 121 sujetos en el estudio, que fueron seleccionados mediante un muestreo no probabilístico de casos consecutivos. Para el cálculo del tamaño de la muestra se utilizó el programa Ene $3.0^{\circ}$ de la Glaxo Smith Kline (GSK).

Para la recolección de datos, estudiantes del primer año de la carrera de Odontología fueron entrenados para realizar las encuestas. Las mismas se realizaron fuera del aula de clase, donde cada encuestador explicó los objetivos del estudio, y previa firma del consentimiento informado y pre-aviso a las autoridades de cada carrera, se aplicó el cuestionario. El mismo contenía 10 preguntas cerradas acerca de posibles mecanismos de prevención de la caries dental. Para la gestión de datos se utilizó estadística descriptiva mediante el programa R 3.0.3 (10) de la R Foundation for Statistical Computing ${ }^{\circledR}$. Para evaluar el conocimiento se agrupó en cinco categorías de conocimiento: Insuficiente [1 - 2 aciertos], Aceptable [3 - 4 aciertos], Bueno [5 - 6 aciertos], Muy bueno [7 - 8 aciertos], y Excelente [9 - 10 aciertos]. Luego se reportó la frecuencia y el porcentaje de respuestas correctas por cada pregunta en tablas.

\section{Resultados}

La muestra quedó conformada por 131 estudiantes, entre los cuales prevaleció el sexo femenino en un $63 \%$, donde el promedio de edad fue de $20 \pm 3$ años. La carrera más representativa fue Medicina, predominando con el $80 \%$ (Tabla 1).

Respecto al nivel de conocimiento, el mayor porcentaje correspondió a la categoría aceptable, aunque ninguno respondió correctamente todas las preguntas o al menos nueve de las diez preguntas (Figura 1).

En cuanto a las respuestas, la mayoría dio razón de que la caries es una enfermedad prevenible. Cabe destacar que solo las tres cuartas partes no consideraron que la caries es una enfermedad transmisible y que los chicles contienen una sustancia que ayuda a prevenirla. Mientras que solamente el $60 \%$ cree que la alimentación influye en la aparición de caries para cierto tipo de alimentos, en tanto, solo el 58,1\% consideró que la técnica de cepillado es lo más importante en la prevención, pues un porcentaje ligeramente inferior consideró que es tan importante la técnica de 
cepillado como la marca del cepillo dental, aunque esta última es una respuesta acertada. Por otro lado, un elevado porcentaje contestó correctamente que el hilo dental sirve como otro elemento diario de higiene junto al cepillo dental y existieron estudiantes que desconocen el uso del hilo dental (Tabla 2).

Tabla 1. Distribución de estudiantes de la Universidad del Pacífico según características demográficas y académicas. Paraguay, 2015

\begin{tabular}{lrr}
\hline Variables & $\boldsymbol{N}^{\mathbf{0}}$ & $\%$ \\
\hline Sexo & & \\
$\quad$ Femenino & 83 & 63,4 \\
$\quad$ Masculino & 48 & 36,6 \\
Procedencia & & \\
$\quad$ Asunción & 77 & 58,8 \\
$\quad$ Gran Asunción & 40 & 30,5 \\
$\quad$ Interior & 14 & 10,7 \\
Facultad & 106 & \\
$\quad$ Ciencias de la Salud & 12 & 80,9 \\
$\quad$ Ciencias de la Comunicación & 11 & 9,2 \\
$\quad$ Ciencias de la Empresa & 1 & 8,4 \\
$\quad$ Ciencias Agropecuarias & 1 & 0,8 \\
$\quad$ Derecho y Ciencias Sociales & & 0,8 \\
\hline
\end{tabular}

Tabla 2. Distribución de respuestas acerca de prevención de caries dental. Estudiantes de la Universidad del Pacifico. Paraguay, 2015.

\begin{tabular}{lrr}
\hline Respuestas & No. & $\%$ \\
\hline ¿La caries dental es una enfermedad transmisible? & 33 & 25,2 \\
Si* $^{*}$ & 75 & 57,3 \\
No & 23 & 17,6 \\
No sabe & 3 & 2,3 \\
¿Es posible prevenir la caries dental? & 128 & 97,7 \\
No & & \\
Si* & 76 & 58,0 \\
En la prevención de caries es importante... & 54 & 41,2 \\
La técnica de cepillado & 1 & 0,8 \\
Técnica de cepillado y un cepillo de marca & \multicolumn{2}{c}{} \\
Un cepillo de marca & 79 & 60,3 \\
¿La alimentación influye en la aparición de caries? & 46 & 35,1 \\
Si, para cierto tipo de alimentos* & 4 & 3,1 \\
Si, para todo tipo de alimentos & 2 & 1,51 \\
No, no tiene ninguna relación & & \\
No sabe & & \\
¿Para qué sirve el hilo dental? & 108 & 82,5 \\
Como otro elemento diario de limpieza bucal junto al cepillo* & 12 & 9,2 \\
Para eliminar la carne que se quedó entre los dientes & 8 & 6,1 \\
Para evitar manchas entre los dientes & 3 & 2,3 \\
No sabe & &
\end{tabular}




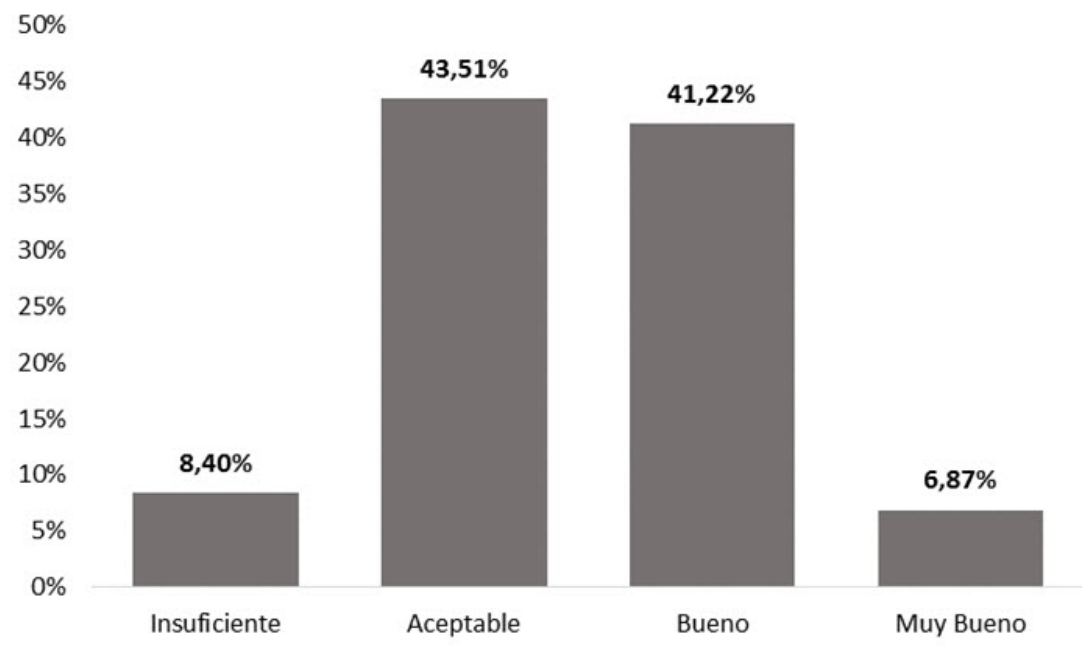

Figura 1. Nivel de conocimiento sobre caries en estudiantes de la Universidad del Pacífico. Paraguay, 2015

Poco menos de la mitad de encuestados respondió correctamente que la edad en que generalmente erupcionan los dientes, es a los 6 años. Más de la mitad consideró que los dientes deben ser limpiados cuando están en boca, esto es; no creyendo necesaria la higiene de la encía y paladar en el bebé. Un bajo porcentaje reconoció la importancia de los dientes primarios para conservar el espacio de los permanentes y muchos desconocían que la bacteria responsable de la caries dental se transmite al compartir con el niño cucharas o utensilios (Tabla 3).

Tabla 3. Distribución de respuestas sobre conocimiento de dientes primarios. Estudiantes de la Universidad del Pacifico. Paraguay, 2015.

\begin{tabular}{llr}
\hline Respuestas & $\mathbf{N}^{\mathbf{0}}$ & $\%$ \\
\hline ¿A qué edad erupciona el primer diente permanente? & 32 & 24,4 \\
3 años & 56 & 42,8 \\
6 años* & 33 & 25,2 \\
9 años & 10 & 7,6 \\
No sabe & & \\
¿Desde cuándo se deben limpiar los dientes del niño? & 76 & 58,0 \\
Desde la salida de los dientes & 26 & 19,9 \\
Desde el nacimiento* & 18 & 13,7 \\
No sabe & 11 & 8,4 \\
Desde que se contagia & & \\
¿Para qué deben ser tratados los dientes primarios cariados? & 46 & 35,1 \\
Para conservar el espacio de dientes* & 31,7 \\
Solo si duele & 31 & 22,9 \\
No sabe & 30 & 18,3 \\
No hace falta porque van a cambiar & 24 & \\
¿Cuándo aparecen las bacterias que dañan los dientes? & & \\
Desde la salida de los dientes & & \\
Desde el nacimiento & 76 & 58,0 \\
No sabe & 26 & 19,9 \\
Desde que se transmite* & 18 & 13,7 \\
\hline
\end{tabular}




\section{Discusión}

Duque de Estrada et al. (11) destacan en su estudio que a diferencia de la mayoría de las enfermedades infecciosas, la caries dental es transmitida verticalmente de la madre al hijo siendo así una enfermedad contagiosa. El Streptococcus mutans de los niños se equipara al de sus madres en el 70\% de las veces. Así también, Da Silva Bastos et al. (12), en su revisión sistemática y meta-análisis encontraron evidencia científica acerca de la transmisión vertical del S. mutans de madre a hijos $(p<0,001)$, mediante métodos de identificación genética se demostró coincidencia de las cepas siendo idéntica el de la madre con su niño.

Por otro lado, en un estudio realizado en la Universidad Federal de Paraíba en Brasil en estudiantes de Pedagogía, el $29 \%$ respondió correctamente que la caries dental es una enfermedad transmisible (13), cifra ligeramente superior al encontrado en este estudio. Así también, el conocimiento acerca de la dentición primaria fue en todos los casos menor al 50\%, destacándose entre ellas que menos del $10 \%$ de los estudiantes desconocía que las bacterias que dañan los dientes aparecen desde que se transmite.

En un estudio realizado en universitarios chinos de Korea del Sur el $67 \%$ consideró que la caries dental es prevenible (14). En cuanto al mecanismo de prevención, en dichos estudiantes el $37 \%$ consideró que la mejor manera de prevención es mediante el cepillado de los dientes, en tanto que, en otro estudio realizado en estudiantes pre-universitarios de la ciudad de Mysore el $88 \%$ sabía que cepillarse adecuadamente ayuda a prevenir la caries dental y los problemas de encías (15).

Por su parte, el estudio realizado en la Universidad Federal de Paraíba en Brasil en estudiantes de Pedagogía el $77 \%$ respondió que es posible tener dientes saludables para toda la vida (13); todas estas cifras inferiores al $97 \%$ encontrado en este estudio. Por otro lado, llama la atención que un poco menos de la mitad de los estudiantes consideró que es tan importante el uso de la crema dental como la técnica de cepillado, proponiendo que este hecho, podría deberse a que se enfatiza su uso mucho mediante la publicidad, sin recalcar en la verdadera importancia del cepillado en la eliminación de placa dental como mecanismo principal de prevención. A todo esto, Tascón y Cabrera (므) resaltan entre los hallazgos de su estudio sobre la etiología de la caries, que el $65 \%$ creía que era consecuencia de la mala higiene oral, $18 \%$ lo atribuía a las bacterias, sólo $7 \%$ cree que se asocia con el consumo de azúcar y $10 \%$ desconocía su etiología.

En un estudio realizado en escolares de 12 y 15-16 años de la Comunidad Valenciana se encontró que el $80 \%$ de los encuestados conocía la capacidad cariogénica de los distintos grupos de alimentos (16). Mientras que, en estudiantes de escuelas secundarias públicas de la Gobernación de Al-Karak el 76,5\% sabía que ciertos tipos de alimentos y bebidas podían causar daño a los dientes (17). Por otro lado, en un estudio piloto realizado en adultos de bajos ingresos en Baltimore, como resultado se obtuvo que el $92 \%$ de los encuestados sabían que el azúcar causa la caries dental (18). Reddy et al. (15), en un estudio realizado en estudiantes pre-universitarios de la ciudad de Mysore, $89 \%$ sabía que los alimentos dulces y pegajosos causan caries dental. Todas estas cifras resultaron superiores al $60 \%$ encontrado en este estudio, que asociaban el consumo de ciertos tipos de alimentos estaría relacionado a la aparición de la caries dental.

Respecto a los elementos coadyuvantes de la higiene bucal, el $82 \%$ de los adultos de bajos ingresos en Baltimore señalaron que la mejor manera de prevenir la caries 
dental era cepillarse y usar el hilo dental todos los días (19). Mientras que sólo el $4 \%$ de los estudiantes pre-universitarios de la ciudad de Mysore tenían conocimiento sobre otras ayudas de higiene oral como hilo dental y enjuague bucal (15). Resultados similar al primer estudio pero muy superior al segundo, pues la mayoría de los estudiantes encuestados conocía el uso del hilo dental.

La evidencia sobre los efectos de los productos de xilitol actualmente no es clara, así como tampoco su eficacia y seguridad. En una revisión sistemática y meta-análisis realizada por Riley et al. (4) en el año 2015 concluye que se requieren más estudios aleatorizados controlados para evidenciar este hecho. Se ha postulado que el consumo de xilitol podría ayudar a prevenir la caries. En cuanto al conocimiento de los estudiantes, solo el $21 \%$ de estudiantes universitarios chinos de Korea del Sur sabía que el xilitol previene la caries (14), similar a lo encontrado en este estudio, acerca de sustancias especiales que podrían ayudar a prevenir la caries dental.

En un estudio realizado en estudiantes de Pedagogía de la Universidad Federal de Paraíba, en cuanto al momento ideal para la visita al odontólogo, el 20\% contestó antes de la salida de los dientes (13), similar a lo reportado en este estudio.

En un estudio realizado en el estado Zulia en Venezuela, para determinar el nivel de conocimiento sobre salud buco-dental en pacientes de 15 años que acudieron a un consultorio, el nivel de conocimiento sobre salud bucodental fue malo en el 51,7\% (19). Cifra que se equipara a conocimientos insuficientes y aceptables de nuestra población.

\section{Conclusión}

Menos de la mitad presentó conocimiento aceptable y ninguno excelente sobre prevención de la caries dental. Llama la atención, que ésta no es mayormente reconocida como una enfermedad contagiosa. Por tanto, en la población de estudio se necesita promocionar la salud bucodental e incrementar los conocimientos sobre el mismo para evitar el progreso de la enfermedad.

\section{Bibliografía}

1. Piovano S. Examen y diagnóstico en cariología. En: Barrancos M, editor. Operatoria Dental. 3ra ed. Buenos Aires: Panamericana; 1999. p. 1176. link

2. Boldorini MG. Cariología. En: Lanata EJ, editor. Operatoria Dental Estética y Adhesión. Buenos Aires: Grupo Guía; 2003. p. 322. link

3. González Sanz ÁM, González Nieto BA, González Nieto E. Salud dental: relación entre la caries dental y el consumo de alimentos. Nutr Hosp. 2013;28(4):64-71. link

4. Riley P, Moore D, Ahmed F, Sharif MO, Worthington HV. Xylitol-containing products for preventing dental caries in children and adults. En: Cochrane Database of Systematic Reviews [Internet]. John Wiley \& Sons, Ltd; 2015 [citado 4 de mayo de 2015]. Disponible en: http://onlinelibrary.wiley.com/doi/10.1002/14651858. CD010743.pub2/full

5. Tascón JE, Cabrera G. Creencias sobre caries e higiene oral en adolescentes del Valle del Cauca. Colomb Med. 2005;36(2):73-78. link 
6. Harris NO. Introducción a la odontología preventiva primaria. En: Harris NO, García-Godoy F, editores. Odontología preventiva primaria. $2^{\text {da }}$ ed. México: Manual Moderno; 2005. p. 530. link

7. Folayan MO, Khami MR, Folaranmi N, Popoola BO, Sofola O0, Ligali TO, et al. Determinants of preventive oral health behaviour among senior dental students in Nigeria. Bmc Oral Heal. 2013;13(1):28. link

8. Ministerio de Salud Pública y Bienestar Social. Encuesta Nacional sobre Salud Oral Paraguay 2008. OPS. Whasington, DC.: Dirección de Salud Bucodental; 2008. link

9. Caballero García, CR, Flores Altorre, JF. Evaluación del Programa: «Salvemos al Primer Molar» y la estrategia PRAT del Ministerio de Salud Pública y Bienestar Social del Paraguay. Asunción: OPS; 2012.

10. R Core Team. R: A Language and Environment for Statistical Computing [Internet]. Vienna, Austria: R Foundation for Statistical Computing; 2014. Disponible en: http://www.R-project.org/

11. Duque de Estrada Riverón J, Pérez Quiñonez JA, Hidalgo-Gato Fuentes I. Caries dental y ecología bucal, aspectos importantes a considerar. Rev Cuba Estomatol. 2006;43(1):0-0. link

12. Da Silva Bastos V de A, Freitas-Fernandes LB, Fidalgo TK da S, Martins C, Mattos CT, de Souza IPR, et al. Reviews: Mother-to-child transmission of Streptococcus mutans: A systematic review and meta-analysis. J Dent. 2015;43(2):181-91. link

13. Soares Ferreira JM, de Lima Targino AC, Soares Forte FD, Corréia Sampaio F. Conhecimento de alunos concluintes de Pedagogia sobre saúde bucal. Interface - Comun Saúde Educ. 2005;9(17):381-388. link

14. Min-Kyoung Park, Hye-Jung Jin, Min-Kyung Lee. Oral Health Knowledge and Perception of Chinese Students' Studying in Korea. Int J Appl Eng Res. 2014:9(24):24953-24960. link

15. Reddy V, Bennadi D, Gaduputi S, Kshetrimayum N, Siluvai S, Reddy CK. Oral health related knowledge, attitude, and practice among the pre-university students of Mysore city. J Int Soc Prev Community Dent. 2014;4(3):154-158. link

16. Almerich Silla JM, Subirá Pifarré C. La salud oral en las personas de edad avanzada. En: El Manual de Odontología. 2.a ed. Barcelona: Masson; 2008. p. 1802.

17. Khamaiseh A, ALBashtawy M. Oral health knowledge, attitudes, and practices among secondary school students. Br J Sch Nurs. 2013;8(4):194-199. link

18. Macek M D, Manski M C, Schneiderman M T, Meakin S J, Haynes D, Wells W, et al. Knowledge of Oral Health Issues Among Low-Income Baltimore Adults: A Pilot Study. J Dent Hyg. 2011;85(1):49-56. link

19. Rivadeneira Obregón AM, Nazco Barrios LE, Hernández Pérez M, Hernández CA. Nivel de conocimiento sobre salud buco-dental. Consultorio 1 ro de marzo. Febrero-octubre 2009. Gaceta Médica Espirituana. 2013;15(1):1-7. link 